\title{
Prospective study on cord bilirubin level as a predictor of Hyperbilirubinemia in term healthy neonates
}

\author{
Bindu A $A^{1}$, Shinoj ${ }^{2}$, Kutty P.M. ${ }^{3}$ \\ ${ }^{1}$ Dr. Bindu. A, Associate Professor, ${ }^{2}$ Dr. Shinoj, Resident, ${ }^{3}$ Dr. P.M. Kutty, Professor and HOD, all authors are \\ attached with Department of Pediatrics and Neonatology, MES Medical College, Perinthalmanna, Malappuram, \\ Kerala, India.
}

Address for Correspondence: Dr. Shinoj, Resident, Pediatrics, MES Medical College, Perinthalmanna, Malappuram. E-mail: binduathoor@yahoo.com

\begin{abstract}
Introduction:Neonatal jaundice or hyperbilirubinemia is a cause of concern for parents and pediatricians, with more than $60 \%$ being affected by this condition in the first few weeks. Prediction of high risk neonates for hyperbilirubinemia will help in developing appropriate follow-up programs for managing the condition. It will also help in reducing duration of hospital stay for low-risk neonates. Objective: To estimate the predictive value of umbilical cord blood bilirubin level for the development of significant hyperbilirubinemia in healthy, full term neonates. Methodology:A prospective study on 450 healthy full tem newborns was undertaken in the postnatal care ward of a tertiary level teaching hospital. The study focused on predictive ability of cord blood bilirubin levels and subsequent development of hyperbilirubinemia. Results:Clinically significant hyperbilirubinemia was detected in 254 out of 450 newborns (56\%) neonates. Majority of participants had cord blood bilirubin levels ranging from $1.5-2.4 \mathrm{mg} / \mathrm{dl}$. Only $1.3 \%$ (3 neonates) had levels $\geq 3 \mathrm{mg} / \mathrm{dl}$. Majority of newborns in our study (60\%) had an intermediate risk of developing hyperbilirubinemia, and only $1.3 \%$ (31) belonged to the high risk category on stratifying risks. Cord bilirubin cut off value of $1.9 \mathrm{mg} / \mathrm{dl}$ predicted subsequent hyperbilirubinemia with sensitivity of $91.8 \%$ and specificity of $52.4 \%$. Conclusion: Study highlights that risk stratification is an excellent method of tracking newborns with hyperbilirubinemia as newborns with hour-specific bilirubin value in low risk zone have reduced risk of developing subsequent significant hyperbilirubinemia. The probability of developing this condition in neonates was not significantly different in males and females.
\end{abstract}

Keywords: Neonatal jaundice, Neonatal hyperbilirubinemia, Cord bilirubin

\section{Introduction}

Hyperbilirubinemia is a very common clinical condition affecting about $60 \%$ of neonates in the first few weeks [1]. These children, who are otherwise healthy, should be monitored as hyper bilirubinemia may affect the central nervous system [2]. Quantifying the level of jaundice has been the foundation for satisfactory management of hyperbilirubinemia.

Visual inspection is not a reliable indicator of serumbilirubin levels. Moreover the current risk factors to recognize infants who are likely torequire treatment for hyperbilirubinemia are not adequate.

Manuscript received: $7^{\text {th }}$ September 2017

Reviewed: $17^{\text {th }}$ September 2017

Author Corrected: $25^{\text {th }}$ September 2017

Accepted for Publication: $30^{\text {th }}$ September 2017
Early discharge from hospital is being practiced for preventing infections, economic constraints of parents, reduced infrastructural facilities in the hospital and some social factors.

But this has increased the risk of significant hyperbilirubinemia that requires readmission and intervention. Some neonates with significant hyperbilirubinemia develop neurological symptoms even without any apparent hemolysis [3].

Prediction of high risk neonates for hyper bilirubinemia will help in developing appropriate follow-up programs for managing the condition. This will also help in reducing duration of hospital stay for low-risk neonates. Risk stratification based 
on cord bilirubin values may help in scheduling timely follow-up after discharge for detection of this condition.

Cut-off value of bilirubin is influenced by factors like ethnicity, child rearing practices and other geosocial factors in a region [4].

Considering the heterogeneity of Indian population, studies from different parts are essential to authenticate the predictive nature and also to evaluate the cut-off value for the population.

The current study aims to estimate the predictive value of umbilical cord blood bilirubin level for the development of significant hyperbilirubinemia in healthy, full term neonates in Kerala.

\section{Methodology}

A total of 450 healthy full term newborns with birth weight $\geq 2.5 \mathrm{~kg}$ was prospectively followed to study the predictive ability of cord blood bilirubin levels and subsequent development of hyperbilirubinemia.

Place and type of study- This prospective study, conducted from January 2014 to June 2015, was undertaken in the postnatal care ward of a tertiary level teaching hospital.

Inclusion criteria- Inborn full term healthy neonates ( $\geq 37$ weeks according to lastmenstrual period) with birth weight $\geq 2.5 \mathrm{~kg}$

Exclusion criteria- Newborns with $\mathrm{Rh}$ incompatibility, presence of significant illness requiring neonatal intensive care unit admission for more than 12 hoursand congenital malformations were excluded from the study.

Detailed evaluation of history, gestational assessment by Expanded Ballard score, and systemic general examination (with particular attention to the factors known to be associated with hyperbilirubinemia) were carried out for all participants. The study was approved by the institutional ethics committee.

Sampling Method- Cord blood was collected from umbilical cord by squeeze method, placed in clot activator vials for analysis of bilirubin level.

Serum bilirubin estimation was done using VITROS TBIL Slide test.

The neonates were followed up clinically every 12 hrs for $72 \mathrm{hrs}$ (till discharge).

Newborns found to have clinically significant jaundice around 72 hours were enrolled in the study and serum bilirubin level was measured at $72 \pm 4$ hours.

Primary outcome was defined as presence of hyperbilirubinemia (total serum bilirubin (TSB) $\geq$ $15 \mathrm{mg} / \mathrm{dl})$.

Based on cord bilirubin levels, newborns were classified into two groups -- Group 1: Serum bilirubin level $\geq 1.9 \mathrm{mg} / \mathrm{dl}$ and Group 2: Serum bilirubin level $<1.9 \mathrm{mg} / \mathrm{dl}$.

Additionally, newborns were divided in three risk zones as given inthe studydone by Bhutaniet al [5].

- High risk zone- Bilirubin level above 95th centile.

- Intermediate risk zone- Bilirubin level between 40th to 95 th centile

- Low risk zone- Bilirubin level less than 40th centile.

Statistical analysis- Maternal and neonatal data were collected in predesigned and pretested proforma.

Sensitivity, specificity, negative and positive predictive values of test were also calculated. Analysis was done using Epi Info.

\section{Results}

Clinically significant hyperbilirubinemia was detected in 254 out of 450 newborns $(56 \%)$ neonates, out of which 27 did not meet the inclusion criteria.

Thus a total of 227 newborns were prospectively followed up during the study period. The maternal characteristics of these children are given in Table 1. 
Table-1: Maternal characteristics of the neonates included in the study.

(PIH - pregnancy-induced hypertension; BOH- bad obstetric history; ROM - Rupture of membranes; CPD Cephalopelvic disproportion).

\begin{tabular}{|c|c|}
\hline Maternal characteristics & $\mathbf{N}(\%)$ \\
\hline \multicolumn{2}{|l|}{ Type of delivery } \\
\hline Cesarean section & $188(82.8 \%)$ \\
\hline Normal vaginal & $34(15 \%)$ \\
\hline Instrumental & $5(2.2)$ \\
\hline \multicolumn{2}{|l|}{ Parity } \\
\hline 1 & $69(30.3)$ \\
\hline 2 & $77(33.9)$ \\
\hline 3 & $54(23.7)$ \\
\hline 4 or more & $27(11.9)$ \\
\hline Oxytocin use & 94(42) \\
\hline \multicolumn{2}{|l|}{ High-risk antenatal factors } \\
\hline $\mathrm{PIH}$ & $30(13.2)$ \\
\hline Diabetes mellitus & $14(6.2)$ \\
\hline $\mathrm{BOH}$ & $13(5.7)$ \\
\hline ROM ( $\geq 18$ hours $)$ & $8(3.5)$ \\
\hline Heart disease & $2(0.9)$ \\
\hline CPD & $2(0.9)$ \\
\hline Others & $22(9.6)$ \\
\hline \multicolumn{2}{|l|}{ Blood group } \\
\hline $\mathrm{O}$ & $95(41.8)$ \\
\hline A & $60(26.4)$ \\
\hline $\mathrm{B}$ & $51(22.4)$ \\
\hline $\mathrm{AB}$ & $11(4.8)$ \\
\hline
\end{tabular}

Pregnancy induced hypertension was the most common among the different high risk factors in mothers, with $13.2 \%$ showing symptoms of this condition. Eight women had rupture of membrane for more than 18 hours.

Most of the neonates (85\%) belonged to the gestational age of 37-39 weeks. Neonatal characteristics of the study population are given in Table 2.

All newborns were exclusively breast fed within two hours of birth. None of the newborns developed kernicterus, or required exchange transfusion. 
Table-2: Neonatal characteristics of the study population.

\begin{tabular}{|c|c|}
\hline Neonatal characteristics & $\mathbf{n}(\%)$ \\
\hline \multicolumn{2}{|l|}{ Sex } \\
\hline Male & $138(61)$ \\
\hline Female & $89(39)$ \\
\hline \multicolumn{2}{|l|}{ Birth weight (g) } \\
\hline $2500-3000$ & $150(66)$ \\
\hline $3000-3500$ & $61(26.8)$ \\
\hline $3500-4000$ & $12(5.2)$ \\
\hline$>4000$ & $4(1.7)$ \\
\hline \multicolumn{2}{|l|}{ Blood group } \\
\hline $\mathrm{O}$ & $84(37)$ \\
\hline A & $70(31)$ \\
\hline $\mathrm{B}$ & $62(27)$ \\
\hline $\mathrm{AB}$ & $11(5)$ \\
\hline \multicolumn{2}{|l|}{ Gestational age (weeks) } \\
\hline 37 & $60(26.4)$ \\
\hline 38 & $73(32.1)$ \\
\hline 39 & $60(26.4)$ \\
\hline 40 & $29(12.7)$ \\
\hline 41 & $5(2.2)$ \\
\hline
\end{tabular}

Cord bilirubin levels in the participants are given in Table 3

Table- 3: Cord bilirubin levels in the participants

\begin{tabular}{|c|c|c|}
\hline Cord bilirubin $(\mathbf{m g} / \mathbf{d l})$ & Number of newborns & Percent \\
\hline $\mathbf{1 - 1 . 4}$ & & 10.5 \\
\hline $\mathbf{1 . 5}-\mathbf{1 . 9}$ & 24 & 40.5 \\
\hline $\mathbf{2 - 2 . 4}$ & 92 & 39.6 \\
\hline $\mathbf{2 . 5 - 2 . 9}$ & 90 & 7.9 \\
\hline $\mathbf{3}$ or more & 18 & 1.3 \\
\hline Total & 3 & $\mathbf{1 0 0}$ \\
\hline
\end{tabular}

Majority of participants had cord blood bilirubin levels ranging from $1.5-2.4 \mathrm{mg} / \mathrm{dl}$. Only $1.3 \%$ (3 neonates) had levels $\geq 3 \mathrm{mg} / \mathrm{dl}$. Cord blood bilirubin levels at $72 \pm 4$ hours are given in Table 4

Table- 4: Bilirubin level at $72 \pm 4$ hours.

\begin{tabular}{|c|c|c|}
\hline Cord bilirubin (mg/d) & Number of newborns & Percent \\
\hline$<\mathbf{5}$ & 3 & 1.3 \\
\hline $\mathbf{5 - 9 . 9}$ & 23 & 10.1 \\
\hline $\mathbf{1 0 - 1 4 . 9}$ & 140 & 61.6 \\
\hline $\mathbf{1 5 - 1 9 . 9}$ & 59 & 25.9 \\
\hline $\mathbf{2 0}$ or more & 2 & 0.9 \\
\hline Total & $\mathbf{2 2 7}$ & $\mathbf{1 0 0}$ \\
\hline
\end{tabular}

Majority of newborns in our study (60\%) had an intermediate risk of developing hyperbilirubinemia, and only $1.3 \%$ (31) belonged to the high risk categoryon stratifying risks (Table 5). 
Table- 5: Risk categorization of neonates based on cord bilirubin levels.

\begin{tabular}{|c|c|c|}
\hline Risk zone & Number of newborns & Percent \\
\hline Low risk(<40th centile) & 59 & 25.9 \\
\hline Low Intermediate risk & 71 & 31.2 \\
\hline High intermediate risk & 66 & 29 \\
\hline High risk (>95th centile) & 31 & 13.7 \\
\hline Total & 227 & 100 \\
\hline
\end{tabular}

A total of 59 newborns had low risk of developing this condition. Considering the arbitrary cut-off value of 15 $\mathrm{mg} \%, 73 \%$ of the participants had more than this value. Among the male newborns $51 \%$ had significant hyper bilirubinemia, which was close to $49 \%$ among female newborns who developed clinically significant form of hyperbilirubinemia. There was no significant difference between genders in the development of this condition.

Clinically significant hyperbilirubinemia was found in $56 \%$ of newborns included in the study. Chi-Square test for cord bilirubin levels at 72 hours is given in Table 6.

Table- 6: Chi-square test for cord bilirubin levels at 72 hours.

\begin{tabular}{|c|c|c|c|}
\hline & $\begin{array}{c}\text { Bilirubin at 72 } \\
\text { hours } \mathbf{2} \mathbf{1 5} \mathbf{m g} / \mathbf{d l}\end{array}$ & $\begin{array}{c}\text { Bilirubin at 72 } \\
\text { hours }<\mathbf{1 5} \mathbf{~ m g / d l}\end{array}$ & 135 \\
\hline $\begin{array}{c}\text { Cord bilirubin } \\
\geq 1.9 \mathrm{mg} / \mathrm{dl}\end{array}$ & 56 & 79 & 92 \\
\hline $\begin{array}{c}\text { Cord bilirubin } \\
<1.9 \mathrm{mg} / \mathrm{dl}\end{array}$ & 5 & 87 & $\mathbf{2 2 7}$ \\
\hline Total & $\mathbf{6 1}$ & $\mathbf{1 6 6}$ & \\
\hline
\end{tabular}

Cord bilirubin levels of the newborns ranged from 1.1-3.8 mg/dL. More than $80 \%$ of the children had cord bilirubin levels in between $1.5-2.4 \mathrm{mg} / \mathrm{dL}$. Cord bilirubin values at $72 \mathrm{~h}$ for two different values showed a positive predictive value of $41.4 \%$ and negative predictive value of $94.5 \%(\chi=-36.0183, p<0.05)$. Sensitivity of the test was $91.8 \%$, and specificity was $52.4 \%$. Thus newborns with cord bilirubin values less than $1.9 \mathrm{mg} \%$ have a reduced risk (5.5\%) of developing clinically significant hyperbilirubinemia. All newborns who had clinically significant hyperbilirubinemia were exclusively breastfed within 2 hours of birth. None of them developed Kernicterus.

\section{Discussion}

In neonates the serum bilirubin levels increases $<5$ $\mathrm{mg} / \mathrm{dl} /$ day and peaks around two to three days [6]. A correlation was found between cord blood bilirubin level and development of hyperbilirubinemia in a population of 423 neonates by Sun et al [7]. Cord blood bilirubin was reported to be a strong predictor of hyperbilirubinemia in neonates in a study conducted by Zeitoun et al [8]. This is a noninvasive technique for which results are available within few hours. Thus, neonates who are at risk of hyperbilirubinemia can be identified before the mother and baby leave the hospital, few days after delivery. On the other hand, identifying high risk neonates will help to reduce the duration of hospital stay for other children who have a low risk of developing hyperbilirubinemia [9].
The cutoff value for prediction of hyperbilirubinemia is different in different studies. Prospective study conducted by Ahire reported that neonates with cord blood bilirubin $\geq 3 \mathrm{mg} / \mathrm{dl}$ should be monitored more frequently [10]. The cut-off point for cord blood bilirubin in full-term neonates was given as $2.15 \mathrm{mg} / \mathrm{dl}$ in another prospective clinical study [8]. Similar value was suggested by Sehgal et al, with a negative predictive value of 0.965 for hyperbilirubinemia [11]. A 99.45\% negative predictive value was assessed for cord bilirubin levels of $<1.89 \mathrm{mg} / \mathrm{dl}$ by Pabbati et al [12]. The negative predictive value was found to reach $99.1 \%$ with a specificity of $98.92 \%$ for cord serum bilirubin level $>4 \mathrm{mg} / \mathrm{dl}$ in a study conducted by Hamdi et al [13]. In the present study, $1.9 \mathrm{mg} / \mathrm{dl}$ was 
used as the optimum cut-off value for predicting hyperbilirubinemia. Cord bilirubin cut off value of $1.9 \mathrm{mg} / \mathrm{dl}$ predicted subsequent hyperbilirubinemia with sensitivity of $91.8 \%$ and specificity of $52.4 \%$. Thus, this cut-off value can predict more than $90 \%$ of the newborns who develop jaundice/hyper bilirubinemia later.

In the current study, $56 \%$ of the newborns had clinically significant hyperbilirubinemia, and cord blood bilirubin ranged from $1.1 \mathrm{mg} / \mathrm{dl}$ to $3.8 \mathrm{mg} / \mathrm{dl}$. Newborns with hyper bilirubinemia had significantly higher levels of cord bilirubin than those without hyperbilirubinemia. These values are in tune with other studies conducted in India, including Dhanjal et al [14]. In our study negative predictive value is more significant, proving that newborn with bilirubin less than cut off value or bilirubin level in low risk zone can be discharged safely and early.

Study also highlights that the risk stratification is an excellent method of tracking newborns with hyperbilirubinemia as newborns with hour-specific bilirubin value in low risk zone have reduced risk of developing subsequent significant hyper bilirubinemia. Sixty one neonates developed significant hyper bilirubinemia requiring phototherapy with no newborn requiring exchange transfusion and none developed kernicterus. Total of 56 had there cord bilirubin levels $\geq 1.9 \mathrm{mg} / \mathrm{dl}$.

Male gender, though known as a risk factorfor developing hyperbilirubinemia,did not show any significant difference from female neonates [15]. Induction of labor using oxytocin also did show a significant relation with cord blood bilirubin levels. The incidence of significant hyperbilirubinemia did not show a significant difference between presence and absence of high risk antenatal factors in mothers.

\section{Conclusions}

Present study show that increased levels of cord blood bilirubin can define a group of neonates who are at risk of developing hyperbilirubinemia. Cord blood bilirubin value $1.9 \mathrm{mg} / \mathrm{dl}$ can be used as an optimum cut-off value to detect more than $90 \%$ of the neonates who are high risk of developing hyperbilirubinemia. The probability of developing this condition in neonates was not significantly different in males and females. Oxytocin-induced labor and high-risk antenatal factors also did not influence the development of this condition in newborns.

Value addition to existing knowledge- This study ascertains the predictive significance of cord blood bilirubin in significant hyperbilirubinemia in neonates. It also helps to validatethe cut-off value of $1.9 \mathrm{mg} / \mathrm{dl}$ as optimum for a population in this region. Further, it also highlights the importance of risk stratification for timely follow-up that will enable detection of hyperbilirubinemia.

Author contributions- All authors were part of the study conducted at the hospital. Manuscript was prepared by DrBindu, with contributions from other authors. All the authors approved the submission of this version of the manuscript and takes full responsibility for the manuscript.

Funding: Nil, Conflict of interest: None initiated, Perission from IRB: Yes

\section{References}

1. Dennery PA, Seidman DS, Stevenson DK. Neonatal hyperbilirubinemia. N Engl J Med. 2001 Feb 22;344(8):581-90.

2. American Academy of Pediatrics. Subcommittee on hyper bilirubinemia. Neonatal jaundice and kernicterus. Pediatrics. 2001;108 (3):763-765.

3. Rosenfeld J. Umbilical cord bilirubin levels as a predictor of subsequent hyperbilirubinemia. J Fam Pract. 1986 Dec;23(6):556-8.

4. Norr KF, NacionK .Outcomes of post partum early discharge.1960-1986, a comparative review. Birth. 1987; 14 (3): 135-141.Doi: 10.1111/j.1523536X.1987.tb01475.x.

5. Bhutani VK, Johnson L, Sivieri EM. Predictiveability of a predischargehour-specific serumbilirubin for subsequent significanthy perbilirubinemia in healthyterm and near-term new borns. Pediatrics. 1999 Jan;103(1):6-14.

6. Gregory P, Martin R, Cloherty P. Neonatal Hyperbilirubinemia. In: Cloherty JP, Eichenwald EC, Hansen AR, Stark AR. Editors. Manual of Neonatal Care. 7thed. New Delhi (India). Wolter Kluwer. 2011. p.304. 
Original Research Article

7. Sun G, Wang YL, Liang JF, Du LZ. [Predictivevalue of umbilical cord blood bilirubinlevel for subsequentneonatal jaundice]. ZhonghuaErKeZaZhi. 2007 Nov;45(11): 848-52.

8. Zeitoun, A, Elhagrasy H, Abdelsatar D. Predictive value of umbilical cord blood bilirubin in neonatal hyperbilirubinemia. Gaz Egypt Paediatr Assoc. 2013; 61(1):23-30.doi: 10.1016/j.epag.2013.04.006

9. Suchońska B, Wielgoś M, Bobrowska K, Marianowski L. [Concentration of bilirubin in the umbilical blood as an indicator of hyper bilirubinemia in newborns]. Ginekol Pol. 2004 Oct; 75 (10):749-53.

10. Ahire N, Sonawane R, Gaikwad R, Patil S, and Sonawane T. Study of correlation of cord blood bilirubin with neonatal hyperbilirubinemia. MVP Journal of Medical Sciences. 2016; 3(1): 60-66. Doi: $10.18311 / \mathrm{mvpjms} / 2016 / \mathrm{v} 3 / \mathrm{i} 1 / 739$.

11. Sehgal P, Wasim S, Chandar V, Gupta A, Rawat A, Kalra V, Pandita N, Bhat N. Cord bilirubin levels as a predictive marker forneonatal hyper bilirubinemia: a prospective study. BMR Medicine. 2017; 81(4).

12. Pabbati J. Umbilical cord blood bilirubin as a predictor for neonatal hyperbilirubinemia. Journal of biomedical and pharmaceutical research. 2014; 3(6). Available at: <http://jbpr.in/index.php/jbpr/ article/ view/357>. Date accessed: 13 Oct. 2017.

13. Hamdi N, Elgayar A, Salah H. Cord blood bilirubin as a predictor of neonatal hyper bilirubinemia. Med. J. Cairo Univ. 2012;. 80 (2): 31-36.

14. Dhanjal GS, Sahni L, Sharma D. A study on cord blood bilirubin levels in a tertiary care centre of Haryana in India. Journal of biomedical and pharmaceutical research. 2013; 2 (5): 62-68.

15. Maisles J, Gifford K, Antle E, Leib R. Jaundice in the healthy newborn infant: a new approach to an old problem. Pediatrics. 1988;81(4):505-11.

How to cite this article?

Bindu A, Shinoj, Kutty P.M. Prospective study on cord bilirubin level as a predictor of Hyperbilirubinemia in term healthy neonates. J PediatrRes. 2017;4(09):552-558.doi:10. 17511/ijpr.2017.i09.03. 